\title{
Single-incision laparoscopic surgery (SILS) for the treatment of ileocolonic Crohn's disease: a propensity score-matched analysis
}

\author{
Valerio Celentano ${ }^{1,2,3}$ [ $\cdot$ Gianluca Pellino ${ }^{4,5}$. Matteo Rottoli ${ }^{6}$. Francesco Colombo ${ }^{7}$. Gianluca Sampietro ${ }^{8}$. \\ Antonino Spinelli ${ }^{9,10}$ • Francesco Selvaggi ${ }^{4}$. SICCR Current status of Crohn's disease surgery collaborative
}

Accepted: 11 December 2020 / Published online: 23 December 2020

(C) The Author(s) 2020, corrected publication 2021

\begin{abstract}
Introduction Single-incision laparoscopic surgery (SILS) aims to minimize the surgical access trauma by reducing the number of abdominal incisions to a single site, potentially offering better cosmetic results and decreased postoperative pain. In this study, we compare the results of SILS ileocolic resection for Crohn's disease (CD) to conventional laparoscopy and open surgery using a propensity score-matched analysis in a retrospective national multicentre study.

Methods All consecutive patients undergoing elective SILS ileocaecal or redo ileocolic resection for primary and recurrent CD from 1 June 2018 to 31 May 2019 were included. Patients were matched 1:1:1 with laparoscopy and open surgery according to perianal disease, recurrent disease, penetrating phenotype of $\mathrm{CD}$, history of previous abdominal surgery, preoperative medical treatment with steroids and anti-TNF. Postoperative morbidity within 30 days of surgery was the primary endpoint.

Results Fifty-eight patients were included in each group, for a total of 174 patients. The conversion rate for SILS and laparoscopy was $10.3 \%$ and $12 \%$, respectively, with no difference in the incidence of postoperative complications (13.8\% and $12 \%, p=0.77)$, whilst open surgery demonstrated a worse morbidity profile, with a complication rate of $25.9 \%(p<0.0001)$. Median length of hospital stay following SILS ileocolic resection was 5 days, significantly shorter compared to 7 days for laparoscopy and 9 for open surgery $(p<0.0001)$.

Conclusions SILS ileocolonic resection for CD demonstrated a comparable morbidity profile compared to laparoscopy in selected patients, with a reduced length of postoperative hospital stay.
\end{abstract}

Keywords Single-incision laparoscopic surgery $\cdot$ Inflammatory Bowel Disease $\cdot$ Crohn's disease

Authorship All authors and affiliations of the SICCR Current status of Crohn's disease surgery collaborative are listed in Appendix 1. Specification of authors' contribution is detailed in Appendix 2. All collaborators to be listed on PubMed.

Valerio Celentano

valeriocelentano@yahoo.it

1 Portsmouth Hospitals NHS Trust, Portsmouth, UK

2 University of Portsmouth, Portsmouth, UK

3 Department of Surgery and Cancer, Imperial College, London, UK

4 Department of Advanced Medical and Surgical Sciences, Universita' degli Studi della Campania Luigi Vanvitelli, Naples, Italy

5 Colorectal Surgery, Vall d'Hebron University Hospital, Barcelona, Spain
6 Surgery of the Alimentary Tract, Sant'Orsola Hospital, Department of Medical and Surgical Sciences, Alma Mater Studiorum University of Bologna, Bologna, Italy

7 General Surgery Unit, Department of Biomedical and Clinical Sciences "L. Sacco", University of Milan, AAST Fatebenefratelli Sacco, Milan, Italy

8 Division of General and HPB Surgery, Department of Surgery, ASST Rhodense - Rho Memorial Hospital, 20017 Rho, Milan, Italy

9 Division of Colon and Rectal Surgery, Humanitas Clinical and Research Center IRCCS, Via Manzoni 56, 20089 Rozzano, Milan, Italy

10 Department of Biomedical Sciences, Humanitas University, Via Rita Levi Montalcini 4, 20090 Pieve Emanuele, Milan, Italy 


\section{Introduction}

Patients with Crohn's disease (CD) are at high risk of recurrence and reoperation following ileocaecal resection. Minimally invasive surgery techniques offer several advantages including reduced postoperative adhesion formation which may facilitate redo surgery [1].

Single-incision laparoscopic surgery (SILS) aims to minimize the surgical access trauma by reducing the number of abdominal incisions to a single incision site, potentially offering better cosmetic results [2] and decreased postoperative pain [3]. However, this procedure is relatively recent, and some variability exists in published studies [2], advocating for more data on the topic. In this study, we compare the results of SILS ileocaecal resection to conventional laparoscopy and open surgery using a propensity score-matched analysis extracted from the national, multicentre study "Current status of Crohn's disease surgery", promoted by the Italian Society of Colorectal Surgery (SICCR).

\section{Methods}

\section{Study settings}

The Italian Society of Colorectal Surgery (SICCR) promoted the snapshot study "Current status of Crohn's disease surgery", which is a retrospective, multicentre, observational study [4] developed according to the STROBE checklist [5]. Ethical approval was obtained from the promoting centres and every participating centre had a named Principal Investigator, liaising with the local ethics committee. Obtaining informed consent from the patients was deemed not necessary by the Ethics Committees in view of the retrospective nature of the study.

\section{Eligibility criteria}

All consecutive patients (aged 16 or older) undergoing elective SILS ileocaecal or redo ileocolic resection for primary and recurrent CD from 1 June 2018 to 31 May 2019 were included. Patients undergoing proctocolectomy, proctectomy or segmental colectomy were excluded from this study. SILS was defined as surgery performed with multiple instruments or trocars introduced via a single incision site, with the choice of commonly available dedicated SILS ports [6] or use of surgical glove-port [7] left to the individual surgeons' preference. Procedures performed with hand-assisted surgery were excluded. If additional trocars were inserted during the SILS procedure, it was considered converted to conventional laparoscopy with intention to treat analysis.

\section{Propensity score-matched analysis}

To compare the results of SILS ileocaecal resections, patients were matched 1:1:1 with laparoscopy and open surgery according to presence of perianal disease, recurrent disease, penetrating phenotype of $\mathrm{CD}$, history of previous abdominal surgery, preoperative medical treatment with steroids and antiTNF.

\section{Study objectives}

Postoperative morbidity within 30 days of surgery was the primary endpoint. Postoperative length of hospital stay (LOS) and stoma rate were the secondary outcome measures.

\section{Statistical analysis}

Categorical variables are presented as frequency and percentages, and were compared using the chi-square test or Fisher's exact test, as appropriate. Continuous variables are presented as mean ( \pm standard deviation) or median (range) according to their distribution, and were compared with the use of Student's $t$ test or the Mann-Whitney $U$ test in case of normal or skewed distribution, respectively. All reported $p$ values were two-tailed, and $p$ values of less than 0.05 were considered to be statistically significant. Statistical analysis was performed by using IBM SPSS Statistics for Windows, version 25.0 (IBM Corp., Armonk, NY, USA).

\section{Results}

Fifty-eight patients were included in each group, for a total of 174 patients. Only 5 patients (8.6\%) in the SILS group had a penetrating phenotype of disease (Table 1).

The conversion rate for SILS and laparoscopy was 10.3\% and $12 \%$, respectively, with no difference in the incidence of postoperative complications (13.8\% and $12 \%, p=0.77)$, whilst open surgery demonstrated a worse morbidity profile, with a complication rate of $25.9 \%(p<0.0001)$. Median LOS following SILS ileocolic resection was 5 days, significantly shorter compared to 7 days for laparoscopy and 9 for open surgery $(p<0.0001)$ (Table 2$)$.

\section{Discussion}

Our study found that patients undergoing SILS for ileocolonic $\mathrm{CD}$ have a similar postoperative morbidity compared to conventional laparoscopic and a shorted LOS. Open surgery demonstrated a twofold increase in postoperative complications and a LOS of approximately 4 and 2 days longer compared to SILS and conventional laparoscopy, respectively. 
Table 1 Baseline characteristics of the included patients

\begin{tabular}{lllll}
\hline & SILS $(n=58)$ & Laparoscopy $(n=58)$ & Open $(n=58)$ & $p$ value \\
\hline Age & $43(20-77)$ & $42(24-79)$ & $48(25-85)$ & $\mathrm{ns}$ \\
BMI & $21.2(17.3-32.6)$ & $23(15-31)$ & $20.5(17-29)$ & $\mathrm{ns}$ \\
Previous surgery & $18(31 \%)$ & $18(31 \%)$ & $18(31 \%)$ & $\mathrm{ns}$ \\
Primary/recurrent & $43 / 15$ & $43 / 15$ & $43 / 15$ & $\mathrm{~ns}$ \\
Penetrating disease & $5(8.6 \%)$ & $5(8.6 \%)$ & $5(8.6 \%)$ & $\mathrm{ns}$ \\
Perianal disease & $11(19 \%)$ & $11(19 \%)$ & $11(19 \%)$ & $\mathrm{ns}$ \\
Preop steroids & $10(17.2 \%)$ & $10(17.2 \%)$ & $10(17.2 \%)$ & $\mathrm{ns}$ \\
Preop anti-TNF & $9(15.5 \%)$ & $9(15.5 \%)$ & $9(15.5 \%)$ & $\mathrm{ns}$ \\
\hline
\end{tabular}

SILS single-incision laparoscopic surgery, $n$ number, BMI body mass index, TNF tumour necrosis factor, $n s$ not statistically significant
Laparoscopy is clearly associated with several short-term benefits in adult and paediatric patients with $\mathrm{CD}$, including shorter time to restoration of bowel function, reduced wound complications and LOS, and better cosmesis [8, 9]. SILS represents a further step forward towards minimally invasive surgery in CD [10], but several aspects related to its feasibility remain debated, particularly in view of specific technical challenges posed by $\mathrm{CD}$ such as the presence of adhesions and internal fistulae, the thickened vascular mesentery and the subtle nature of some multisite small bowel strictures [11].

It is important to consider that only few studies have been published to date concerning SILS in CD with reported variability in several aspects of the procedure. A review of 11 studies, including 369 patients, identified differences in the indication for surgery and the type of port and camera used [2]. Several reports included patients in whom additional trocars were placed or a hand-assisted procedure has been described. Postoperative morbidity ranges between 4.1 and $18.8 \%$ following SILS for $\mathrm{CD}$, with reoperation rates not exceeding $6 \%$, and an average LOS of 4-11 days [2]. A multicentre study compared the outcomes of SILS with that of conventional laparoscopy for ileocaecal CD, and found that SILS was associated with reduced postoperative pain and analgesia requirements [3]. However, SILS might be less suitable for complex CD operations as for example patients requiring additional procedures such as multiple bowel resections or strictureplasties.

The findings of our study confirm that SILS is currently applied in a selected group of $\mathrm{CD}$ patients, as we found a rate of penetrating disease of only $8.6 \%$, with a relatively high rate of ileostomy formation (13.8\%) in this cohort of patients undergoing elective surgery. The number of patients requiring an ileostomy in the SILS group was doubled compared to laparoscopy, but it did not reach statistical significance, likely due to the small sample size. The ileostomy rate is an important key performance indicator in CD surgery, and must be evaluated in prospectively maintained databases.

Table 2 Surgical outcomes

\begin{tabular}{|c|c|c|c|c|}
\hline & SILS $(n=58)$ & Laparoscopy $(n=58)$ & Open $(n=58)$ & $p$ value \\
\hline Conversion & $6(10.3 \%)$ & $7(12 \%)$ & N/A & 0.77 \\
\hline Ileostomy & $8(13.8 \%)$ & $4(6.9 \%)$ & $8(13.8 \%)$ & 0.22 \\
\hline LOS & $5(3-20)$ & $7(4-15)$ & $9(4-66)$ & $<0.0001$ \\
\hline Complications & $8(13.8 \%)$ & $7(12 \%)$ & $15(25.9 \%)$ & $<0.0001$ \\
\hline Details of complications & $\begin{array}{l}3 \text { intra-abdominal collections } \\
\text { treated with antibiotics, } \\
2 \text { chest infections } \\
1 \text { bleeding requiring transfusions } \\
2 \text { wound infections }\end{array}$ & $\begin{array}{l}1 \text { anastomotic leak } \\
2 \text { urinary infections } \\
2 \text { small bowel obstructions } \\
\text { treated conservatively } \\
2 \text { bleeding requiring } \\
\text { transfusions }\end{array}$ & $\begin{array}{l}2 \text { chest infections } \\
1 \text { DVT } \\
4 \text { anastomotic leaks } \\
1 \text { small bowel injury } \\
1 \text { CVC sepsis } \\
3 \text { wound infections } \\
1 \text { small bowel obstruction } \\
\text { treated conservatively }\end{array}$ & \\
\hline Readmissions & 0 & 0 & $1(1.7 \%)$ & 0.32 \\
\hline Reoperations & 0 & $\begin{array}{l}1(1.7 \%) \\
\text { for anastomotic leak }\end{array}$ & $\begin{array}{l}4(6.9 \%) \\
3 \text { for anastomotic leak } \\
1 \text { for small bowel resection }\end{array}$ & 0.04 \\
\hline
\end{tabular}

SILS single-incision laparoscopic surgery, $n$ number, $L O S$ length of hospital stay, $N / A$ not applicable, $D V T$ deep vein thrombosis, $C V C$ central venous catheter 
We must acknowledge as a limitation of our study the risk of information and recall bias, due to the retrospective design and also the self-reported nature of our data from many different centres. It is possible that patients undergoing conventional laparoscopy or open surgery had a more technically challenging procedure, or reached surgery in a more deconditioned status compared to the SILS group. However, the propensity score-matched analysis allowed comparison of CD patients with similar characteristics undergoing ileocolonic resection in the three different groups, obtaining meaningful results to support the use of SILS in selected patients. Data on Patient-Reported Outcome Measures (PROMs) was not included despite it may provide an essential role when deciding between surgical approaches in patients with $\mathrm{CD}$. We previously demonstrated that the anastomotic technique or configuration does not affect $\mathrm{CD}$ postoperative morbidity as a single causative factor [12], and similarly it is important to highlight the need for multidisciplinary-led decision-making to offer the most appropriate surgical approach tailored to the specific characteristics of the individual patient, moving the focus from a single causative factor (i.e. anastomotic technique, preoperative treatment) to a multifactorial approach.

\section{Conclusions}

SILS ileocolonic resection for CD demonstrated a comparable morbidity profile compared to laparoscopy in selected patients, with a reduced length of postoperative hospital stay.

Supplementary Information The online version contains supplementary material available at https://doi.org/10.1007/s00384-020-03821-6.

\section{Compliance with ethical standards}

Conflict of interest The authors declare that they have no conflict of interest.

Open Access This article is licensed under a Creative Commons Attribution 4.0 International License, which permits use, sharing, adaptation, distribution and reproduction in any medium or format, as long as you give appropriate credit to the original author(s) and the source, provide a link to the Creative Commons licence, and indicate if changes were made. The images or other third party material in this article are included in the article's Creative Commons licence, unless indicated otherwise in a credit line to the material. If material is not included in the article's Creative Commons licence and your intended use is not permitted by statutory regulation or exceeds the permitted use, you will need to obtain permission directly from the copyright holder. To view a copy of this licence, visit http://creativecommons.org/licenses/by/4.0/.

\section{References}

1. Celentano V, Sagias F, Flashman KG, Conti J, Khan J (2019) Laparoscopic redo ileocolic resection for Crohn's disease in patients with previous multiple laparotomies. Scand J Surg 108(1): 42-48

2. Maeda K, Nagahara H, Shibutani M, Fukuoka T, Inoue T, Ohira M (2019) A review of reports on single-incision laparoscopic surgery for Crohn's disease. Surg Today 49(5):361-368

3. Carvello M, de Groof EJ, de Buck van Overstraeten A, Sacchi M, Wolthuis AM, Buskens CJ, D'Hoore A, Bemelman WA, Spinelli A (2018) Single port laparoscopic ileocaecal resection for Crohn's disease: a multicentre comparison with multi-port laparoscopy. Color Dis 20(1):53-58

4. SICCR Current status of Crohn's disease surgery collaborative (2020) National variations in perioperative assessment and surgical management of Crohn's disease: a multicentre study. Color Dis. https://doi.org/10.1111/codi.15334

5. von Elm E, Altman DG, Egger M, Pocock SJ, Gøtzsche PC, Vandenbroucke JP, STROBE Initiative (2008) The Strengthening the Reporting of Observational Studies in Epidemiology (STROBE) statement: guidelines for reporting observational studies. J Clin Epidemiol 61(4):344-349

6. Kumar CVP (2011) Different types of single incision laparoscopy surgery (SILS) ports. J Laparosc Surg 4:47-51

7. Livraghi L, Berselli M, Bianchi V, Latham L, Farassino L, Cocozza E (2012) Glove technique in single-port access laparoscopic surgery: results of an initial experience. Minim Invasive Surg 2012: 415430, 4 pages

8. Pellino G, Keller DS, Sampietro GM, Angriman I, Carvello M, Celentano V, Colombo F, Di Candido F, Laureti S, Luglio G, Poggioli G, Rottoli M, Scaringi S, Sciaudone G, Sica G, Sofo L, Leone S, Danese S, Spinelli A, Delaini G (2020) Selvaggi F; Italian Society of Colorectal Surgery SICCR. Inflammatory bowel disease position statement of the Italian Society of Colorectal Surgery (SICCR): Crohn's disease. Tech Coloproctol 24(5):421-448. https://doi.org/10.1007/s10151-020-02183-Z

9. Pellino G, Keller DS, Sampietro GM, Annese V, Carvello M, Celentano V, Coco C, Colombo F, Cracco N, Di Candido F, Franceschi M, Laureti S, Mattioli G, Pio L, Sciaudone G, Sica G, Villanacci V, Zinicola R, Leone S, Danese S, Spinelli A, Delaini G, Selvaggi F, the Italian Society of Colorectal Surgery (SICCR) (2020 Feb) Inflammatory bowel disease (IBD) position statement of the Italian Society of Colorectal Surgery (SICCR): general principles of IBD management. Tech Coloproctol 24(2):105-126. https://doi.org/10.1007/s10151-019-02145-0

10. Heeney A, O'Connor DB, Martin S, Winter DC (2010) Single-port access laparoscopic surgery for complex Crohn's disease. Inflamm Bowel Dis 16:1273-1274 Back to cited text no. 15

11. Maggiori L, Panis Y (2014) Laparoscopy in Crohn's disease. Best Pract Res Clin Gastroenterol 28:183-194

12. Celentano V, Pellino G, Spinelli A, Selvaggi F, Current status of Crohn's disease surgery collaborative (2020) Anastomosis configuration and technique following ileocaecal resection for Crohn's disease. A multicentre study. Updates Surg 2020. Online ahead of print

Publisher's note Springer Nature remains neutral with regard to jurisdictional claims in published maps and institutional affiliations. 